POSMODERNIDAD 



\title{
De la oligarquía austera a la anarquía feliz. Consideraciones acerca de la posmodernidad
}

\author{
María Elia Gutiérrez Mozo \\ Universidad de Alicante, España \\ Recibido: 1 de julio del 2018 / Aprobado: 2 de agosto del 2018 \\ doi: 10.26439/limaq2019.n005.4525
}

\begin{abstract}
En su ancestral disposición de servicio a la habitación humana, la arquitectura actual compite con una suerte de habitaciones virtuales, ajenas a lo inmediato y tangible que ha sido su propio territorio a lo largo de milenios y a lo ancho de este planeta. Persuadir al internauta para que vuelva a encontrarse consigo mismo y con su entorno, reconocerse en su yo y en su circunstancia, inseparables uno de la otra, es el reto al que se enfrenta el arquitecto, con todas las de perder, pero empeñado en ganar. Este escrito se propone, mediante el diagnóstico provisional acerca de la situación "descolocada" de la arquitectura del tercer milenio, compartir la esperanza de un nuevo "encuentro en la primera fase" de la habitación humana. Para ello, recorre los libros de referencia en los que se definió la posmodernidad y los relaciona con los rasgos que, todavía hoy, la caracterizan.
\end{abstract}

posmodernidad, arquitectura, habitación humana, arquitectos, usuarios, productores, consumidores

\section{From austere oligarchy to happy anarchy. Considerations on postmodernity}

In its ancestral service provision to human habitation, current architecture competes with other types of virtual habitation, alien to the immediacy and tangibility of its own territory over thousands of years around the world. Against overwhelming odds, but committed to win, architects confront with the challenge of persuading internet users to find themselves and their environment again by recognizing themselves in their self and circumstance, which are inseparable from each other. Through a provisional diagnosis of the "misplaced" situation of the third-millennium architecture, this paper aims to share the hope of a new "encounter of the first kind" of human habitation. To this effect, it explores reference books defining postmodernity and connects them to the features that, still nowadays, characterize it.

postmodernity, architecture, human habitation, architects, users, producers, consumers

1 Paráfrasis del título de la película de Steven Spielberg, Close Encounters of the Third Kind (Estados Unidos, 1977), que en España se tradujo como Encuentros en la tercera fase. 


\section{INTRODUCCIÓN, OBJETIVO Y MÉTODO}

Posmodernidad es una palabra que fue inventada cuando el siglo pasado doblaba su ecuador. De una palabra se espera que designe un hecho, una situación o una cualidad.Y así fue en un principio: quienes la propusieron, o le dieron la bienvenida, le asignaron un cierto significado compartido que quedó impreso en unos pocos libros.

En esos escritos, se hacía referencia a hechos contemporáneos que avalaban de algún modo y acreditaban el sentido de lo que venía al mundo de la cultura y de la crítica en calidad de afortunado neologismo. Respondía a unos hechos reales.Y daba cuenta, sobre todo, de uno que quizás sea su más sólida razón de ser y de subsistir: que la modernidad, fuera cual fuera el valor que se le otorgase y el peso profesional y social que se le atribuyera, había establecido un antes y un después irreversibles en la cronología de los acontecimientos. O dicho de otro modo: que la historia no sería en adelante la cuestión a la que dar la cara, como había hecho el siglo XIX, o volver la espalda, como quiso hacer el segundo cuarto del veinte. La posmodernidad ni se comprometía con el pasado, que bien pasado estaba, ni auguraba un futuro de inevitable desconcierto.

Dos grandes guerras y una revolución de por medio en el espacio de medio siglo habían procurado una sola convicción que se cernía sobre las conciencias en Europa y en el mundo: nada iba a ser como antes. Los "códigos", clásicos o modernos, serían en adelante papel mojado, quedarían en el baúl de los recuerdos; tanto el hombre de Leonardo, prendido en la geometría del círculo y el cuadrado, como el de Le Corbusier, que proclama la "sección áurea" en Le modulor (1950). La posmodernidad les da la espalda.

Ni pasado "historicista" ni "vanguardia" futurista. La posmodernidad se conforma con el presente, huidizo. De ahí la dificultad de definir lo que por vocación se proclama indefinido e indefinible.Y es el propósito que asume este artículo: el de, en ausencia de un pautado común, apuntar rasgos que nos ayuden a entender lo que acontece.

Partiremos, pues, de los (pocos) libros que son responsables del concepto desde su origen, para seguir luego el rastro de los hechos que, por una parte, 
los corroboran, y si, por otra, no los desmienten, desde luego los desbordan. La posmodernidad, en efecto, solo tiene como coordenadas en común el "después" al que alude el prefijo. Ni siquiera el tiempo la redime de su ser arbitrario: siendo sus hechos "contemporáneos", no lo son debido a sus distintas y distantes latitudes. Antes o después no es lo mismo aquí o allá.

De ahí que la posmodernidad apunte maneras distintas en lugares distintos. Su único sello, si lo hay y se deja ver, es el de ciertos autores estelares (Hadid o Gehry se hallarían entre ellos) que, allá donde instalan su obra, dejan su huella. Otros, en cambio (Herzog \& De Meuron), alardean de que su marca consiste en carecer de ella: no hay "yo", todo es "circunstancia".

En ese sentido, uno de tantos, la posmodernidad marca distancia con la modernidad. Si para esta el "yo" lo supuso casi todo (Wright, Le Corbusier, Mies y alguno más tuvieron egos arrasadores), para aquella las circunstancias deciden. Tiempo y lugar, alza o baja en los mercados, sorpresa e impacto son determinantes.

Sería ingenuo suponer, sin embargo, que es la vinculación al mercado lo que pone a su disposición los productos de la arquitectura que algunos arquitectos nos obstinamos en llamar obras. Ese vínculo se remonta, como tarde, al tiempo de los faraones. Y pasa por Felipe II y Luis XIV. La diferencia no está en el vínculo. El matrimonio de conveniencia de arquitectura y poder (Sudjic, 2007) es de lo más estable, ya que en él prima el interés económico. Lo insólito radica en el mercado global que hoy abarca el planeta y lo convierte en aldea incivil.

De los mercados locales, feudos y principados, cecas y zocos, monarquías y repúblicas, comunas y bolsas a los que prestaron sus servicios las arquitecturas locales afincadas en sus lugares respectivos, solo queda, más que el recuerdo, el residuo.Y de sus arquitecturas, en el mejor de los casos, algún monumento, cuando no una ruina.

Ello ha inducido en este ancestral oficio una fatal "desorientación". No nos sorprende que algunas de sus manifestaciones lo sean en calidad de fantasmas (esos que Vitrubio atribuía a la pura teoría). En el fondo, aun materializadas y con alto coste, son utopías: ajenas al lugar en el que, por avatares del negocio, han tomado - que no hecho- asiento. 
Su vocación es "estelar" (como la de algunos de sus autores).Y no porque el "globo" al que alude la susodicha aldea sea observatorio, como lo fue la Einsteinturm de Mendelsohn en Potsdam (paradigma singular de la modernidad en su primavera), o como lo fue, en la Antigüedad, la geometría de las pirámides, sino porque se observa a sí mismo como inquilino de un universo ya no inasequible: pieza de astronomía, no de arquitectura. $\mathrm{Si}$ cabe imaginar una arquitectura astral, HAL, el personaje de 2001: A Space Odyssey (Kubrick, 1968), sería su modelo.

\section{REVISIÓN DE LA LITERATURA}

A él apunta con certera intuición el libro que tomaremos como punto de partida y que data de 1948: Mechanization Takes Command de Siegfried Giedion. Giedion, que ya había saltado a la primera plana con su tributo a la modernidad clásica Space, time and architecture. The growth of a new tradition (1941, revisado en 1967), toma nota del nuevo avance de la máquina, que va más allá de la metáfora (la "máquina de habitar" de Le Corbusier) y se erige en artefacto visible (moderado en Bankunion, de Corrales y Molezún [1975] en Madrid, y provocador en Pompidou, de Piano y Rogers [1977] en París). En adelante, los equipos mecánicos no serán entrañas del inmueble que haya que ocultar.

Entre tanto se suceden diversos testamentos del pasado: milenario el de Le Corbusier en Le modulor, que ve la luz en 1950, y reciente en el de Wright, cuyo Testamento — con ese título - aparece en 1957. Son paradigmas ambos de cómo la modernidad, diciendo renegar del pasado clásico, lo honra y corrobora con todas sus fuerzas.

En 1960, Reyner Banham publica una oportuna — a juzgar por su caladorecensión de lo ocurrido en el medio siglo transcurrido, bajo el título de Theory and Design in the First Machine Age, en el que retoma en cierto modo el argumento de Giedion. En ella, y volviendo la mirada a los prolegómenos del Movimiento Moderno, advierte cómo las utopías futurista y constructivista, asumidas como "primera edad", acaso habían sido algo más que locas fantasías que la Bauhaus había aparcado, atenta a otros intereses, pero que los nuevos tiempos iban a poner en marcha. 
Uno de los primeros gestos de esa puesta en marcha sería el que apuntaba, seis años después, el mismo autor en su libro The New Brutalism (Banham, 1966). Significaba, entre otros conceptos, un retorno a lo concreto y particular (el magnetismo del lugar) desde lo abstracto y genérico (la creación de espacio).

Con el brutalismo se abría de hecho, y tal vez sin plena conciencia de ello, una de las rutas hacia la posmodernidad: mediante la forma construida (dicen proponerse los Smithson en su texto de 1957), hacer significativos el cambio, el crecimiento, el flujo y la vitalidad de la comunidad. No se trata de crear una nueva lengua o código, sino de proveer nuevos modos de hablar.

Pero el golpe de gracia a los postulados del Movimiento Moderno vendría de la mano de un libro que causó sensación en su momento y que daba la razón a Vitrubio cuando decía que la arquitectura civil se debe, sobre todo, a la "oportunidad". Nos referimos a Complexity and Contradiction in Architecture, de Robert Venturi (1966). No podía imaginar su autor hasta qué punto su "más no es menos", revocando el "menos es más" de Mies, iba a desatar el desenfreno de la nueva era.

Si algo puede decirse, sin temor a errar, del medio siglo que la posmodernidad lleva a la espalda es que sus productos son complejos (nada simples, desde luego) y contradictorios (por supuesto) y nada lógicos (al menos en su factura: la lógica del mercado se debe a otra instancia que la razón no conoce).

Lejos de la casuística venturiana, demasiado ingenua quizá (aprender de Las Vegas no nos seduce a estas alturas), los hechos que atribuimos al modo de ser posmoderno corroboran los supuestos del "aprendiz de todas las cosas". Por supuesto, con no pocas salvedades. Pero estas no dejan de ser hechos "singulares" en el panorama global de la arquitectura actual: de su naturaleza sabremos en la década siguiente, los años setenta, por el discurso de Charkes Jencks.

En la segunda mitad de los sesenta, dos nuevos libros de autores italianos, editados ambos en Bari, apuntaron al futuro y al pasado del momento — todavía confuso, pero no consciente, y menos habiéndolo asumido- de su propia confusión: son Architettura come mass-medium, de Renato de Fusco (1967), y Teorie e storia dell'architettura, de Manfredo Tafuri (1968).

En el segundo, el autor desmonta el equívoco que conduce a confundir la mirada a la historia con hacer historia. Su tesis es que nada es tan antihistórico 
como una actitud, y no digamos una pasión, historicista. Con ello previene, aunque quizás con poca fortuna, sobre los desvíos de una posmodernidad prendida, y prendada, de "guiños" a la historia.

En el primer libro, se nos describe una obviedad que, sin embargo, nos será útil para poder ponderar las consecuencias de una arquitectura rendida a las masas, y consiguientemente a su espectáculo: una clientela transeúnte que, lejos de rodearla, visitarla y habitarla, la curiosea.Y se sorprende sin más si acaso.

Y en la misma década, todavía en los sesenta — años dominados por la imagen que, desde el tiempo de la Ilustración, no ha dejado de crecer-, el Grupo Archigram surtió al imaginario de la arquitectura de la ciudad con modelos que, a su manera y por medio de la revista que llevaba su mismo nombre, respondían a las instancias preponderantes del momento: la movilidad (Walking City, 1963), la ciudad a modo de macroinstalación (Plug-in-City, 1964), la libre elección (Control and Choice, 1967) o el presente efimero (Instant City, 1969). Ninguna de estas sugerencias caerá en saco roto, como no sea que la posmodernidad se entienda como ese saco roto en el que todo cabe, pero no permanece.

Pero es en los setenta cuando, como hemos apuntado, se perfila, si no una teoría (lo que ni es factible ni se pretende), sí al menos un diagnóstico y un perfil de lo que se prevé que va a acontecer tras la decadencia del espíritu de la modernidad.Y se los debemos a Charles Jencks.

En Architecture 2000 (1971), el autor señala dos vías a los nuevos tiempos de la arquitectura: lo tardomoderno y lo posmoderno. Sería tardomoderno aquello que, sin abjurar de lo moderno, toma a su cargo uno de sus principios y trata de llevarlo al límite de sus posibilidades formales. Si la función ha de prevalecer, que lo haga a toda costa. Si la forma es pura geometría abstracta, que lo sea sin concesiones. Si los equipos mecánicos gobiernan la vivienda, que la máquina de habitar no sea una mera metáfora, sino un hecho visible.

La otra opción, propiamente posmoderna, trataría de "templar" los rigores del Movimiento Moderno concediendo audiencia a la historia y sus tradiciones y figuras, con ironía quizá, pero con legítima nostalgia. El mismo Jencks precisará su discurso después en su nuevo libro, The Language of Post-modern Architecture (1977). 
Como si se barruntara que va a ser la posmodernidad la fórmula, o mejor, la ausencia de ella lo que va a cundir en el panorama arquitectónico del nuevo milenio.Y es que, en efecto, los tardomodernos (entre los que, por ejemplo, cabría ubicar a los minimalistas) van a ser minoría (aun contando con casos notables).

En los mismos setenta y entre las dos citadas y muy precisas publicaciones, hemos de referirnos a dos autores cuya obra escrita desborda la propia obra edificada: Aldo Rossi, cuyos Scritti scelti sull'architettura e la città aparecen en 1975, y Christopher Alexander, que tras sus Notes on the Synthesis of Form (1964) sorprende a sus lectores con el giro dado en A Pattern Language (1977). En la terminología de Jencks, Rossi sería un posmoderno y Alexander un tardomoderno.

Con su atención a la ciudad, es obvio que Rossi, quizá más convincente en sus libros que en sus edificios y barrios, rescata la imperativa herencia de la historia, a la que la modernidad había dado la espalda bajo el dilema de o crear un nuevo barrio entero (Törten) o irse a las afueras (Villa Savoye).

Alexander, por el contrario, fiel a las demandas de la función, halla en el "lenguaje de patrones" modelos universales de soluciones supuestamente lógicas, que lo son en abstracto, pero cuya lección no va más allá de ser lo que es: referencia atendible e inimitable. Lo válido en un lugar puede no serlo en otro.Y se da la paradoja de que lo universal en lo local desautoriza lo local. La aldea global dará en su día cuenta de ello.

Abandonamos ahora (en el umbral de los años ochenta) el rastreo de lo escrito a propósito de una posmodernidad todavía presunta, a sabiendas de que un diluvio de literatura anegará en adelante la arquitectura producida en los últimos treinta y tantos años. Y lo hacemos con el convencimiento de que los supuestos obtenidos de los "precursores" son esclarecedores, en cuanto no están contaminados por los hechos que más tarde los confirman o los desmienten, pero en ningún caso los mediatizan y confunden.

La literatura que, en la última generación, viene adjetivando los fenómenos varios de la arquitectura en curso, antes sirve - como dijo Aldo Pellegrini en un libro de 1965 - "para contribuir a la confusión general" que para otra cosa. Casi siempre laudatoria y de panegírico, como no sean escritos de 
altercado (que no debate) entre las partes beligerantes, forma parte del paquete que el mercado en cada ocasión trata de vendernos. $\mathrm{Y}$ carece en absoluto de la mínima discreta distancia que el juicio requiere para su consideración como tal.

Hace dos milenios, Vitrubio escribió que, en arquitectura, como en todo (cum in omnibus rebus), hay dos cosas: lo que se significa (quod significatur) y lo que significa (quod significat). Es decir: la obra edificada y lo escrito acerca de ella. Da por sentado, con su acreditado espíritu pragmático, que el significante y el significado tendrán que corresponderse.

Nada más lejos de la posmodernidad, uno de cuyos emblemas, la deconstrucción, desautoriza ese supuesto: la arquitectura -en proyecto la mayoría de las veces o algunas de ellas edificada siguiendo lo establecido- desafia lo escrito y, queriendo o sin querer, se burla de ella: un lenguaje (el arquitectónico) parodia al otro (verbal).

\section{DISCUSIÓN Y CONCLUSIONES}

Para corroborarlo, veamos unos pocos rasgos que caracterizan las circunstancias a las que responde, todavía hoy, la denominación de posmodernidad.

\section{I. İ́conos en la aldea global}

Que la arquitectura anduvo siempre vinculada a alguna suerte de comercio es un lugar común: de la renacentista Zecca veneciana a la protomoderna Bolsa de Ámsterdam, no pocas de sus obras maestras obedecen a este reclamo. Lo nuevo no es que la arquitectura se conciba como mercancía: lo insólito es su ubicuidad, que contradice su naturaleza "local". Así, la utopía, como la máquina a la que Giedion otorga ese liderazgo, "toma el mando" en un sentido literal: está en todas partes y, por ello, no está en ninguna. Es de todos y de nadie. 
"Patrimonio de la humanidad", se podrá predicar de ella con ironía. Herencia del planeta. “¿De qué tiempo es este lugar?”, rezaba un clásico de la modernidad. Posmoderno aspira a ser "de después", que es como decir "más allá de". El arquitecto que acierta a encajar su producto se siente de vuelta al Olimpo: su obra desafía los umbrales de lugar y tiempo.

\section{Posición y postura}

"Seréis como dioses", dijo a Adán y Eva la serpiente en el Paraíso. Sois como dioses, dice el mercado a los star-architects que esplenden en el firmamento mediático. Y lo sois en virtud de vuestros íconos que dan la vuelta al mundo, cuya "posición" poco importa si su "postura" es seductora, si la imagen (el postureo) acierta a hacerse lugar, no en este u otro lugar, sino en el imaginario utópico de quienes la contemplan y archivan. Que esté en las pantallas de millones de usuarios virtuales será su definitiva (y efímera) acreditación.

Cabría que ingenuamente se confundiera la postura, que se atribuye a la imagen, con la "compostura" que los clásicos (Alberti, 1485/1977) daban como sello de calidad de la mejor arquitectura, concebida a la medida del cuerpo humano. Nada que ver. Las posturas, cuando no imposturas, con las que juegan ciertos modelos posmodernos son, por así decirlo, contorsiones que pregonan su inestabilidad por fortuna aparente. Su deconstrucción es pura pirueta que, tras haber desconcertado al espectador, le aburre.

Hacer gala de inestabilidad es uno de los artificios de la imagen. Jugó a ella la Tribuna de Lenin, diseñada por El Lissitzki en la edad dorada del Constructivismo — de cuyas rentas saca provecho la posmodernidad-, y la insinúa la estatua de Kolbe, que, reflejada en el estanque, pone un punto de inquietud en la quietud beatífica del Pabellón de Mies.

El culto al ícono consiente; en efecto, libertades que el rigor tectónico nunca se quiso permitir, aunque acaso las apeteciera: véanse los arbotantes de las catedrales. Entre unas y otro, la posmodernidad, aliada con una tecnología, si no omnipotente, desde luego poderosa, se decanta por aquellas, en aras de su eficiencia simbólica. 
Se diría que, en su dependencia de la imagen, se mira en el espejo de las "artes visuales", multiplicadas por el vuelco dado a sus medios debido al avance del emporio digital. Nada más lejos de la realidad: basta que leamos en clave virtual Los diez libros de arquitectura, de Alberti (1977), para percatarnos de cuán ajeno está nuestro concepto del ver, linear y medir del humanista. Tanto como el robot (la mecanización toma el mando) del hombre de Leonardo. Nuestros saberes "transversales" no nos hacen competentes en el campo de las humanidades.

Lo fueron los maestros de la modernidad, a pesar - y esa es la paradoja - de su voluntad de reconducir la arquitectura a su estricta disciplina. No lo son los estrategas del posmodernismo. De hecho, contradiciendo los códigos tanto de lo moderno como de lo clásico, nos hacen ver cuánto hubo en común, y hay, entre lo uno y lo otro.

Lo cásico había sido (siempre) moderno y lo moderno fue (seguía siendo) clásico. En la medida de las cosas y en su pasión por la geometría. En su afición numérica decimal, no digital, y en su clara definición del espacio. En sus disposiciones y sus composiciones. En su reconocida vocación abstracta y en su asunción ilustrada de la norma del gusto.

\section{Dimensión y desmesura}

Todos los elementos de la enumeración del apartado anterior son valores que la posmodernidad encierra en el baúl de los recuerdos. Claro está que el gusto no ha sido abolido por decreto. Simplemente no cuenta como no sea a título estrictamente individual. Cuestión reservada al arquitecto e irrelevante en el juicio de la arquitectura que, desde el momento en que se asume como objeto de consumo, escapa a la sensibilidad del productor y se hace deudora de sus presuntos consumidores. Bien entendido que, como advertía Voltaire, el buen gusto es el más raro de los valores.

Uno de sus beneficios, como es el de educar, ni pasa por las mientes de los gestores del mercado inmobiliario. De arruinar la sensibilidad 
de las audiencias se encargan sin tregua los medios. Y la arquitectura de ningún modo se sustrae a esas escuelas permanentes e implacables, beligerantes incluso, y desde luego contaminantes, del mal gusto.

Pero cerremos el paréntesis abierto a la sensibilidad y sus derechos y volvamos a los dictados de la razón y de los números, que, paradójicamente, el sistema digital y binario ha deslegitimado. Pues medir no equivale a contar: en la medida hay comparación. La medida es concreta cuanto la contabilidad es abstracta. De hecho, los dígitos nos trasladan de lo conmensurable - el numerus que Alberti invoca en la base de su tratado De re aedificatoria - a lo inconmensurable: de la medida a lo desmedido.

La desmesura es uno de los atributos del ícono posmoderno, a la que se suman cierta "indefinición" que el imaginario no solo permite, sino propicia, y una "descolocación", en sí misma y en su entorno, que favorece la provocación que se espera. Se contraviene así la trilogía del código clásico: número, definición y colocación. Y el corolario que sigue a tales principios, la concinnitas albertiana, es abolido desde el momento en el que las pantallas reemplazaron a los edificios e hicieron de la "desproporción" su santo y seña.

Una imagen fuera de proporción es semejante a sí misma (en el peor de los casos, es su caricatura) y sigue siendo perfectamente reconocible.

La geometría da un paso atrás o adelante, según se mire. Pues a la euclídea — vigente en la modernidad (la Villa en Garches de Le Corbusier no es menos rigurosa, a este respecto, que el Partenón) y suscrita al punto, la recta y el plano- la sucede la fractal, que se amolda a lo aleatorio (un litoral, por ejemplo) con la misma comodidad con la que un registro digital toma nota de los infinitos matices de una melodía intrincada. Toda forma, pues, urdida por los juegos de la fantasía (Pollack, 2005) es susceptible de representación y reproducción.

Proyecto y ejecución encuentran en el medio digital la vía libre para la puesta en obra de toda invención que haya caído en gracia en el consenso político y mediático. 


\section{Construcción y deconstrucción}

La ejecución que mencionamos, contaminada por el descrédito del lenguaje y sus incertidumbres semiológicas, hace suyos los postulados de la deconstrucción lingüística y juega a desarticular la única verdad en la que clásicos y modernos habían cifrado la naturaleza tectónica de la arquitectura como hecho construido. Esto, inevitablemente, convierte la estructura del edificio, su firmitas, en tramoya y trampantojo, de efecto tan eficaz como efímero. Si el suelo y el vuelo fueron los parámetros de la edificación que las leyes aspiraban a regular, el espíritu posmoderno se desentiende de uno y otro: del suelo, dándolo por apto a priori, y del vuelo, fingiéndolo cuanto los medios lo consienten. Ciertas utopías de los sesenta (la ciudad marina de Kikutake o la arquitectura aérea de Ruhnau y Klein) lo habían presagiado.

\section{Del armario a la pantalla}

La ingravidez es un sueño que la arquitectura viene acariciando desde el origen de los tiempos. El Movimiento Moderno, que nunca fue popular (la posmodernidad trata de serlo), quiso hacer enseña de ella reduciendo la fábrica a geometría: del desafio de Wright en la Fallingwater al modelo neoplástico de la Schröder Haus. De las poderosas terrazas americanas al armario habitable holandés. La levedad del mueble versus el aplomo del inmueble: un dilema que los posmodernos resuelven evadiéndolo por la tangente de la imagen.

El ícono no pesa (como no sea en bits). Lo subrayaba a sus alumnos, en los años ochenta, John Hejduk, uno de los Five Architects, en una lección magistral: nadie que mira un cuadro se apresura a sostenerlo para que no se caiga. Si algo pesa en el cuadro, es el marco. Se nos olvida, sin embargo, que la arquitectura es el marco (el passe-partout que diría Derrida).

Ocurre, sin embargo, que en el mundo mediático en curso el marco es el lienzo. O, por decirlo de otro modo, el marco es todo, solo hay marco. La pantalla, que no es ni inmueble ni mueble, es hoy lo que fue el armario de Rietveld. La posmodernidad vive, y sobrevive, en las pantallas. 


\section{Instalación versus habitación: alrededor y adentro}

La red nos tiende sus redes. Todo cabe a condición de que cada cual renuncie a ser quien es; es decir, se sustraiga al acto original de la habitación humana, el de habitarse uno mismo en el propio cuerpo (Heidegger hace hincapié en ello), lo que ha sido modelo y módulo de arquitecturas, clásicas y modernas.

El anonimato, irresistible tentación que asalta al internauta, es incompatible con el principio de habitación, que se identifica con el reconocer y el reconocerse. Por otra parte, la amenaza de desahucio del planeta invita a un comportamiento eremita que no parece viable ni rentable bajo ningún concepto.

Pero, aun dando la espalda a los intereses de la arquitectura, la pregunta es esta: ¿acaso habitar es imprescindible para la especie humana, como lo es para el resto de los seres vivientes? De momento, lo único que podemos decir es que no hacerlo, es decir, estar en un perpetuo tránsito o trance, es, como poco, agotador y destructivo. Consumiendo sin parar, el consumidor transeúnte se consume, sin haber consumado su propia vida que, además, no ha sido suya.

Desasistida de una clientela con vocación de habitar, deshabitada, no es raro que la arquitectura vuelva los ojos a la "instalación" como réplica cabal a la curiosidad del transeúnte. Si estamos de paso y, en caso de demorar en alguna parte, nuestras "moradas" son virtuales, una instalación será la perfecta posada para ese tránsito: valdrá la pena recorrerla o simplemente rodearla, pero no se nos pasará por la cabeza habitarla; una instalación, o montaje, en la que no cuenta el adentro, sino el alrededor. El Guggenheim de Bilbao no vale por lo que alberga, sino por el impacto que ejerce sobre su entorno. El ícono se debe a los medios y al medio: nunca a sí mismo.

\section{El relato digital}

Lo que cuenta y se cuenta es todo lo que hay.Y lo que se cuenta es el propio hecho de contarlo. De ahí la decisiva importancia del relato digital que la obra deberá conformarse con no desacreditar. Pues, antes que ella haya llegado a ser, él habrá dado la vuelta al mundo y convencido de su "realidad", en la que lo virtual sobreabunda y supera con creces a lo real. 
El star system, uno de los estandartes de la posmodernidad, sería inconcebible sin el fundamento informático y mediático que lo sustenta. En ese firmamento estelar, el proyecto ha dejado de ser prólogo de la obra para hacer de ella un epílogo suyo. Como Piranesi con sus grabados hizo famosos los monumentos de la Antigüedad, usurpándoles parte de su gloria, los 3D acaparan los triunfos de la arquitectura y, si no mueven a las masas, suscitan de entrada sus entusiasmos.Y airean desde luego el nombre de sus promotores.

\section{Los medios y el medio}

Subyace a este comercio, justo o injusto, una guerra sin cuartel entre los medios y el "medio" que es, desde su origen y por naturaleza propia, la arquitectura. ¿Cuál de ellos es, en el presente, el que la sociedad prefiere como lugar favorito de habitación o de demora, al menos, transitoria?

Pendientes de toda una constelación de pantallas, somos sonámbulos en casa, en el barrio y en la ciudad. Los medios nos han sustraído al medio. El arca naufraga en el diluvio.

\section{Público y privado: ideas y emociones}

Nada o poco que objetar en un mundo de ideas. Menos aún en un caos de ideologías. Pero ¿qué decir de las emociones, esas que se adhieren a lo tangible, más allá, o más acá, de lo visible? El 3D deja verlo todo, lo visible y lo oculto, desde todos los ángulos posibles, arriba y abajo, moviéndose a través de lo hueco y de lo macizo, como habitante fantasma, libre de las miserias corporales, ajeno a la gravedad y sus leyes, dueño del espacio y el tiempo. Pero ¿qué se toca? ¿Qué se roza? ¿Con qué se tropieza? ¿Qué pesa?

Pesar. Pesar es acción mecánica, pero es asimismo emoción. ¿Es que no hay emoción que no sea deudora de la visión? ¿Acaso no puedo vivir la arquitectura, y sentirla, con los ojos cerrados? ¿Dónde está la arquitectura del ciego, habitante en la oscuridad y de la oscuridad? ¿Dónde la arquitectura del que duerme o, sencillamente, se recuesta o toma asiento? 


\section{El yo y su circunstancia}

Persuadir al internauta para que vuelva a encontrarse consigo mismo y su entorno, reconociéndose en su yo y su circunstancia (cuerpo y arquitectura) inseparables, es el reto al que se enfrenta hoy el arquitecto: con todas las de perder, pero empeñado en ganar.

\section{REFERENCIAS}

Alberti, L. B. (1977). Los diez libros de architectura [trad. Francisco Lozano, ed. facsímil].Valencia: Albatros. (Trabajo original publicado en 1485)

Alexander, C. (1964). Notes on the synthesis of form. Cambridge: Harvard University Press.

Alexander, C. (1977). A pattern language. Nueva York: Oxford University Press.

Banham, R. (1960). Theory and design in the first machine age. Londres: Architectural Press.

Banham, R. (1966). The new brutalism. Londres: Architectural Press.

De Fusco, R. (1967). Architettura come mass-medium. Bari: Dedalo Libri.

Giedion, S. (1941). Space, time and architecture. The growth of a new tradition. Cambridge: Harvard University Press.

Giedion, S. (1948). Mechanization takes command. Nueva York: Oxford University Press.

Jencks, Ch. (1971). Architecture 2000: prediction and methods. Londres: Studio Vista.

Jencks, Ch. (1977). The language of post-modern architecture. Nueva York: Rizzoli.

Kubrick, S. (productor y director). (1968). 2001: A space odyssey [película]. Estados Unidos: Metro-Goldwyn-Mayer. 
Le Corbusier (1950). Le modulor. Boulogne-sur-Seine: L'Architecture d'Aujourd'hui.

Pellegrini, A. (1965). Para contribuir a la confusión general. Buenos Aires: Nueva Visión.

Pollack, S. (director). (2005). Sketches of Frank Gehry [película]. Estados Unidos: Sony Pictures Classics.

Rossi, A. (1975). Scritti scelti sull'architettura e la città. 1956-1972. Milán: Cooperativa Libraria Universitaria del Politécnico de Milán.

Smithson, A., y Smithson, P. (1957). Cluster city, a new shape for the community. The Architectural Review, 122(11), 333-336.

Spielberg, S. (director). (1977). Close encounters of the third kind. Estados Unidos: Columbia Pictures; EMI Films; Phillips Productions.

Sudjic, D. (2007). La arquitectura del poder. Barcelona:Ariel.

Tafuri, M. (1968). Teorie e storia dell'architettura. Bari: Laterza.

Venturi, R. (1966). Complexity and contradiction in architecture. Nueva York: Museum of Modern Art.

Wright, F. L. (1957). A testament. Nueva York: Horizon Press. 